\title{
As condições de realização da propriedade
}

Diego José Baccin ${ }^{1}$

CONGOST, Rosa. Tierras, leyes, história: estudios sobre “La gran obra de la propiedad”. Barcelona: Crítica, 2007. 347 p.

A pesquisadora Rosa Congost, em Tierras, leyes, história: estudios sobre “La gran obra de la propiedad”, realiza uma compreensão distinta acerca dos direitos de propriedade. Sua abordagem consiste em uma perspectiva analítica comparada, que contrasta a realidade sóciohistórica espanhola à francesa e à inglesa. Nesse livro, a autora situa os leitores sobre as diferentes possibilidades de se compreender a propriedade, denunciando entendimentos eminentemente abstratos e apresentando uma análise sobre as condições de realização da propriedade a partir da dinâmica das relações sociais.

Catedrática de História Econômica na Universidade de Girono (Catalunha), Rosa Congost tem investigado, em suas pesquisas, problemas relacionados a temáticas dos direitos de propriedade, transformações agrárias, relações sociais e desigualdades. Seus estudos têm uma interdisciplinaridade com outras áreas do conhecimento social, dentre as quais se destacam o direito e a sociologia. É autora de diversas publicações que congregam questões relacionadas à dinâmica de interesse do campo historiográfico do mundo rural e valoriza o enfoque de pesquisa regional.

Seu livro Tierras, leyes, história: estudios sobre "La gran obra de la propiedad" foi publicado em 2007, pela editora Crítica, em Barcelona. Originalmente publicado em língua espanhola, ainda não conta com tradução para o português. As sínteses sobre a obra são escassas, não havendo muitas publicações nesse sentido, mas o trabalho é constantemente referenciado entre os historiadores sociais que projetam pesquisas no campo da história do mundo rural.

Outro dado sobre a pesquisadora é que, ao lado de outros estudiosos, ela integra a comissão organizadora do Atelier Pierre Vilar. Resumidamente, o pensamento desse historiador pode ser caraterizado em cinco aspectos: a) sua atualidade efetiva e do marxismo que preceitua, a despeito de modas intelectuais; b) as preocupações metodológicas sobre a necessidade da análise histórica e da abordagem das estruturas das sociedades estudadas; c) o encorajamento ao trabalho concreto no terreno da pesquisa; d) a necessidade de intercâmbio com o conjunto

\footnotetext{
${ }^{1}$ Doutorando em História pelo Programa de Pós-graduação em História (UPF), membro do Núcleo de Estudos Históricos do Mundo Rural (NEHMuR), Bolsista CAPES I.
} 
das ciências sociais; e) a pedagogia cidadã em relação ao pensar historicamente de uma ciência em construção.

É possível considerar que esses aspectos do pensamento de Pierre Vilar são desenvolvidos nos estudos de Rosa Congost principalmente no que concerne às preocupações metodológicas, à valorização documental e ao reconhecimento da necessidade de diálogo dos historiadores com outras áreas das ciências sociais. Além disso, a presença dessas reflexões contribui para a compreensão de um processo histórico em permanente construção. Dessa forma, acredito não ser mera casualidade que "La gran obra de la propriedade” seja dedicada a Pierre Vilar.

A epígrafe do livro é composta por um texto de Marc Bloch: "Propiedad, propietarios, cuántos malentendidos pueden devivarse de estas palavras!”. Se há mal-entendidos sobre a propriedade e as formas de ser proprietário, o livro de Rosa Congost consegue construir uma interpretação acerca da propriedade, não meramente como ideia, mas como obra, ou seja, como resultado de uma multiplicidade de ações que criam e recriam as condições de realização da propriedade, formulando novos entendimentos sobre os mal-entendidos.

Como elemento central, o livro apresenta a percepção de que o direito de propriedade não deve ser entendido somente enquanto ideia, mas como obra. Nesse sentido, a autora espanhola aponta que seu livro não deve ser concebido necessariamente como denúncia (por mais que também o seja) e reivindica a necessidade de se estudar ou analisar historicamente o processo empírico de construção da propriedade, o qual irá relativizar a ideia construída acerca de uma propriedade-metáfora, abstrata, para uma propriedade-problema, fruto das relações sociais que constituem tanto o direito quanto a propriedade em cada contexto.

A primeira advertência da autora, nesse sentido, se debruça sobre o aspecto de pensar a propriedade como ideia. Essa constatação perpassa o que a autora pretende denunciar, ou seja, a ideia de uma noção de propriedade única, absoluta, perfeita, linear, sagrada, nominalista e estadista. Aceitar essa ideia de propriedade é considerar a existência indiscutível de uma única forma de ser proprietário.

Em sua narrativa, Rosa Congost busca demonstrar que aceitar essa tese significa assumir uma visão simplista ou reducionista do processo histórico, não admitindo a existência de outros direitos de propriedade que não aqueles impostos e consagrados pelos códigos produzidos nos séculos XIX e XX. Fazer isso, em sua percepção, é aceitar uma definição indiscutível do direito de propriedade, criado por jurisconsultos, protegido e assegurado pelo Estado, efetivado pelas revoluções burguesas e consagrado pelo direito positivo liberal. 
A historiadora ainda enfatiza que assumir e aceitar essa ideia é alimentar a ilusão de uma propriedade definida à margem das relações sociais, o que reforça a ideia de um único sentido das relações entre a lei e a sociedade. Além disso, adotar tal postura significa desconsiderar que as decisões dos legisladores sempre tendem a obedecer ao interesse de poucos - os privilegiados - e não leva em conta que a propriedade se constitui a partir do processo de ação possessória dos sujeitos a partir de suas práticas sociais.

A segunda advertência é justamente o caminho que a pesquisadora desenvolve propriamente em seu estudo, que é pensar “La gran obra de la propiedad”, ou seja, pensar a propriedade como obra. E é isso que se busca denunciar, ou seja, uma visão, uma ideia, um discurso sobre a propriedade aparentemente neutro que contamina a compreensão do processo histórico. Nessa direção, pensar a propriedade enquanto obra - isso é, como uma realidade móvel, dinâmica, em contínua construção - é pensar sobre as condições de realização da propriedade.

“La gran obra da la propiedad” é o esforço de pensar a propriedade como processo das relações sociais, constatando a necessidade de conceber a propriedade como reflexo, produto e fator das relações sociais existentes. Sua motivação e ânimo seria de "lançar a dúvida sistemática” sobre todos os discursos em relação à propriedade voltados tão somente a justificar a ordem existente.

Assim, a propriedade-metáfora é a síntese abstrata de uma ideia de propriedade construída pelo direito nos códigos do século XIX e XX ratificada pelo Estado liberal de forma monolítica. Já a propriedade-problema se refere às condições de realização dos direitos de propriedade, que acenam para as pluralidades das práticas de propriedade e as formas de apropriação diversas, sejam elas privadas ou comunitárias.

São campos em disputa que perpassam a construção social do direito de propriedade a partir das relações estabelecidas entre esses campos na perspectiva de "evolução” dos direitos de propriedade no acesso de grupos sociais ao reconhecimento de suas práticas apropriativas. Tais práticas se apresentam de formas diversas, mas a historiadora considera que é dessa heterogeneidade que se desenvolvem as condições de realização da propriedade.

O livro está dividido em três partes, e cada parte está subdividida em três capítulos, em um total de nove. As três partes estão assim intituladas: ¿Qué derechos? ¿Qué história?, Sagrada propiedad imperfecta e La gran obra de la propiedad. A primeira parte, conforme a autora, é aparentemente mais teórica e incide na apresentação de uma reflexão que pode ser aplicada para o exame de qualquer realidade histórica, fixando-se sobre a análise dos direitos de propriedade, 
o debate historiográfico espanhol sobre a revolução liberal e aquilo que a autora chamou de processo de desmascarar o discurso e a constituição da propriedade única.

A segunda e a terceira partes analisam aspectos mais concretos relacionados com a propriedade da terra. A segunda parte se inicia com o tema da propriedade imperfeita, entendida como a propriedade compartilhada (ou talvez coletiva), tendo como referência o modelo francês. Essa seção trata da Sagrada propiedad imperfecta e discute questões relacionadas à constituição da propriedade espanhola, inspirada na ideia do modelo francês no século XIX, discurso assumido como do próprio nascimento nas propriedades nesse país, a relação entre proprietários, ou talvez posseiros enfiteutas e seu processo de resistência em relação ao domínio senhorial na região Catalã e o tema das desapropriações com ênfase na Galícia e Catalunha.

A terceira parte, La gran obra de la propiedad, trata do individualismo agrário e toma como referência o modelo inglês. Essa seção denuncia uma perspectiva de história comparada à utilização da justificativa do crescimento econômico como sendo uma espécie de álibi que abalizaria o processo de privatizações de muitas propriedades. De forma específica, aborda questões relacionadas à análise das terras de usos comunais, consideradas “perdidas” e a constituição dessa em propriedade privada relacionada a atitudes de classe, dando atenção também aos chamados “el espigueo” e às suas implicações na perspectiva de sua compreensão na dimensão de uma história comparada.

Algumas seções dos capítulos já haviam sido apresentadas em eventos ou tinham sidos publicadas anteriormente. Esse é o caso, por exemplo, da primeira parte - Direitos de propriedade e análise histórica “¿Qué derechos? ¿Qué história?” -, cuja primeira versão foi apresentada no X Congresso de História Agrária, realizado em Sitges (Barcelona) em 2002. Outro caso é o do capítulo sete, que trata sobre as práticas de justiça e direitos de propriedades em relação às atitudes de classe, que havia sido publicado pela Revista Études Rurales.

As reflexões contidas no livro subsidiam a discussão de um debate atual que envolve a ideia de propriedade e as diferentes formas de exercer esse direito, a partir do lugar de proprietário. Nesse sentido, a perspectiva compreensiva de uma propriedade enquanto obra contribui para o entendimento sobre as origens da concepção moderna de propriedade, e, com isso, se realiza uma crítica em relação à ideia construída de propriedade em contraste com as práticas possessórias de grupos sociais concretos, levando em consideração épocas e regiões específicas.

O livro, portanto, “reivindica” a necessidade de se pensar a história da propriedade com ênfase na compreensão das condições de realização da propriedade. Visa um duplo sentido: por 
um lado, desmistificar, dessacralizar concepções estáticas e imutáveis de uma propriedade como ideia abstrata legalista e estadista. De outro, realizar a transposição de uma propriedade a ser definida nas relações sociais, de uma propriedade enquanto obra.

\section{Referências}

COHEN, Arón; CONGOST, Rosa; LUNA, Pablo F. (Org.). Pierre Vilar uma história total uma história em construção. Bauru, SP: Edusc, 2007. 368 p.

CONGOST, Rosa. Tierras, leyes, história: estudios sobre "La gran obra de la propiedad". Barcelona: Crítica, 2007. 347 p.

MACHADO, Ironita A. P. (2017). Rosa Congost - Historia, el derecho y la realidad de las construcciones sociales en la gran obra de la propiedad. Revista História: Debates e Tendências, v. 17, n. 2, p. 374-384, 1 jul. 2017. 